\title{
Mario Bunge, Systematic Philosophy and Science Education: An Introduction
}

\author{
Michael R. Matthews
}

Published online: 29 August 2012

(C) Springer Science+Business Media B.V. 2012

\begin{abstract}
Mario Bunge was born in Argentina in 1919 and is now in his mid-90s. He studied atomic physics and quantum mechanics with Guido Beck (1903-1988), an Austrian refugee and student of Heisenberg. Additionally he studied modern philosophy in an environment that was a philosophical backwater becoming the first South American philosopher of science to be trained in science. His publications in physics, philosophy, psychology, sociology and the foundations of biology, are staggering in number, and include a massive 8-volume Treatise on Philosophy. The unifying thread of his scholarship is the constant and vigorous advancement of the Enlightenment Project, and criticism of cultural and academic movements that deny or devalue the core planks of the project: namely its naturalism, the search for truth, the universality of science, the value of rationality, and respect for individuals. At a time when specialisation is widely decried, and its deleterious effects on science, philosophy of science, educational research and science teaching are recognised, and at a time when 'grand narratives' are thought both undesirable and impossible - it is salutary to appraise the fruits of one person's pursuit of the 'Big' scientific and philosophical picture or grand narrative. In doing so this special issue brings together philosophers, physicists, biologists, sociologists, logicians, cognitive scientists, economists and mathematicians to examine facets of Mario Bunge's systematic philosophy and to appraise its contribution to important issues in current philosophy and, by implication, education.
\end{abstract}

A decade ago I wrote an account of Bunge's life, achievements and publications as an Introduction for a Science \& Education special issue on 'Philosophy and Quantum Theory' (Matthews 2003). The publication of five books and $20+$ articles in the subsequent decade means that the account then given of his publications is somewhat outdated. The 2003 journal special issue had a constrained focus on the history of debate about quantum theory and Bunge's own contribution to that debate. This 2012 special issue is concerned with the

M. R. Matthews $(\square)$

School of Education, University of New South Wales, Sydney 2052, Australia

e-mail: bondi_mike@hotmail.com 
wider picture of the very possibility of systematic philosophy in the postmodern age and the era of academic specialisation.

Evaluating Mario Bunge's systematic philosophy provides an opportunity to examine a number of contemporary issues concerning the institution and practice of philosophy, the possibility of liberal education, and ideals of good science-teacher education. First, as Bunge is an exemplary exponent and defender of 'grand narratives' in philosophy, an examination of his own systematic version of philosophy is an opportunity to appraise the postmodernist claim that such endeavours cannot and should not be undertaken. Second, as Bunge is a trained physicist an examination of his philosophical work is an opportunity to appraise the claim that philosophy of science is best done by those with knowledge and competence in science. Third, as Bunge clearly embodies the aspirations held for liberal education, so an appraisal of his work can amplify and refine those goals of cross-disciplinary knowledge and depth of understanding. Fourth, if Bunge's melding of philosophy and physics is seen to be productive, indeed even necessary, then there are challenges for science teacher-education programmes to produce teachers with such competences and interests.

\section{Bunge's Life and Achievements}

Willard Van Orman Quine, in his autobiography, mentions attending the 1956 South American Philosophical Congress in Santiago, Chile. The only thing about the meeting that he thought worth recording was his observation that:

The star of the philosophical congress was Mario Bunge, an energetic and articulate young Argentinian of broad background and broad, if headstrong, intellectual concerns. He seemed to feel that the burden of bringing South America up to a northern scientific and intellectual level rested on his shoulders. He intervened eloquently in the discussion of almost every paper. (Quine 1985, p. 266)

The congress was held nearly 60 years ago when Bunge was in his mid-30s; he is now approaching his mid-90s with his intellectual energy only little diminished. Bunge is the author of more than 50 books and 500 scientific and philosophical papers. Bunge writes on an enormous range of subject matters-philosophical foundations of physics, philosophy of quantum mechanics, philosophy of mind, materialism, philosophy of biology, foundations of mathematics, Newtonian mechanics, explanation in social science, ethics in science, science education, science and religion, etc. What distinguishes Bunge's æuvre is its consciously systematic nature and it is this systematic agenda which will be appraised in this special issue.

Mario Bunge was born in Buenos Aires in 1919. From an early age Bunge was set a demanding schedule by his liberal and politicised parents of reading literature in six languages: Spanish, English, French, Italian, German and Latin. This early multi-lingual ability was of inestimable benefit to his education, allowing him to read the classics and the best moderns in their own words. It also freed him from dependence on commercial and ideological judgements about what books would be translated and published in Spanish. Argentina in the 1920s and 1930s was far more a closed society than an open one; it was dominated by right-wing politics (Argentina supported Hitler's fascism and maintained diplomatic relations with Germany through to 1944), and by the reactionary Catholic Church which took its guidance from Pius IX's 1864 anti-modernist, anti-liberal Syllabus of Errors encyclical. 
In 1943, Bunge started to work on problems of nuclear and atomic physics under the guidance of Guido Beck (1903-1988), an Austrian refugee, a student of Heisenberg, the inventor of the layer model of the atomic nucleus, the first to propose the existence of the positron, and a teacher who Bunge thanks for 'teaching me not to allow politics to get in the way of my science' (Bunge 1991, p. 524). Bunge obtained his PhD in 1952 from the University of La Plata with a dissertation on the kinematics of the relativistic electron; the dissertation was published as a book in 1960. Subsequently he, alone or jointly with his former student Andrés Kálnay and other scientists, published several articles on a number of problems in quantum mechanics: the total spin of a system of particles, the mass defect of the $\mathrm{H}$ atom, new constants of motion, the quantum Zeno paradox, the measurement process, etc. (Bunge 1944, 1945, 1955, 1956).

In the early 1950s Bunge worked for half a year with David Bohm in São Paulo. Bohm one of the stellar figures of theoretical physics had been forced out of Princeton and the USA by McCarthyite pressures. In 1956 Bunge, who had come to reject Bohm's account of quantum mechanics, was appointed a professor of theoretical physics at the universities of Buenos Aires and La Plata. In 1957 he won the chair of philosophy of science at the University of Buenos Aires, and a year later he resigned his physics chairs to concentrate on philosophy. However after being forced out of Argentina by the military junta he went back to teaching both physics and philosophy during short-term appointments in the USA prior to becoming a professor of philosophy at McGill University in Canada in 1966.

Bunge has published a staggering amount across a spectrum of subjects. Among his English-language books are: Causality: The Place of the Causal Principle in Modern Science (1959), Intuition and Science (1962), The Myth of Simplicity (1963), Scientific Research (1967c, d), Foundations of Physics (1967b), Philosophy of Physics (Bunge 1973a, b), The Mind-Body Problem (1980), Scientific Materialism (1981), Philosophy of Psychology (1987, with R. Ardila), the Treatise on Basic Philosophy (eight volumes, Bunge 1974a-1989), Finding Philosophy in Social Science (1996), Foundations of Biophilosophy (with Martin Mahner 1997), Social Science Under Debate: A Philosophical Perspective (1998), Philosophy of Science (2 vols.) (1998), The Sociology-Philosophy Connection (1999), Crisis and Reconstruction in Philosophy (Bunge 2000a, b), Emergence and Convergence (2004), Chasing Reality: Strife over Realism (2006), Political Philosophy (2009), Matter and Mind: A Philosophical Inquiry (2010), and Evaluating Philosophies (2012c). Many of these books have appeared in Spanish, Portuguese, German, Italian, French, Polish, Russian and Hungarian editions.

His contribution to this 2012 journal special-issue-'Does Quantum Physics Refute Realism, Materialism and Determinism?' well captures the central thread of Bunge's scholarly life: namely, studying and learning from the interaction of science and philosophy, and then reconciling and defending the best of both. Quantum theory has engaged philosophers more than perhaps any other scientific theory. As one physicist/philosopher has written:

The development of quantum mechanics led to the greatest conceptual revolution of our century and probably to the greatest that mankind had ever experienced. It most likely exceeded the great revolutions in our thinking brought about by the Copernican revolution, the Darwinian revolution, and the special as well as the general theory of relativity. Quantum mechanics forced us to reconsider our deepest convictions about the reality of nature. (Rohrlich 1987, p. 136)

Not surprisingly the theory has parented hosts of popular and professional philosophical misunderstandings; it seems that every ontological and epistemological position what so ever has been drawn from the empirical success of quantum mechanics. On this topic 
Bunge rejected both the Copenhagen and the Bohm understandings and proposed his own realist interpretation. This keeps the mathematical formalism but modifies the positivist interpretation proposed by Bohr, Heisenberg, Pauli, and Born. For instance, Bunge interprets the square of the absolute value of the state function not as the probability of finding the object in question in a unit volume (an intrinsically subjective notion), but as the probability of its being there (an objective notion). Bunge argues that electrons and the like are neither particles nor waves, although they appear as such under special circumstances. Talk of waves and particles is metaphorical, an allusion back to classical notions from which quantum mechanics emerged. He coined the term 'quanton' to denote these non-classical entities, and maintains that mature quantum theory has no need for the classical metaphors, just as mature electrodynamics has no need for mechanical analogs. As he writes in his contribution to this issue:

when the quantum theory is freed from its philosophical grafts, it is realized that it is just as realistic, materialist, and deterministic as classical physics. What is true is that it forces us to update our ontology. In particular, it forces us to broaden the concepts of matter and determination, to downgrade the concepts of shape and individuality, and to reinforce the systemicity principle - due to the ubiquity of entanglement and de-coherence.

Bunge's style is also manifest previous articles published in Science \& Education: 'Is Religious Education Compatible with Science Education' (Mahner and Bunge 1996), 'Energy: Between Physics and Metaphysics' (Bunge 2000a), 'Twenty-Five Centuries of Quantum Physics: From Pythagoras to Us, and from Subjectivism to Realism', (Bunge 2003) and 'Knowledge: Genuine and Bogus' (Bunge 2011). These essays demonstrate his philosophical method and concern for systematic knowledge: namely attention to detail, using logic to the fullest possible extent to achieve clarity of thought and to separate sound from unsound arguments, and striving to achieve a holist and coherent intellectual position whereby ontology, metaphysics, epistemology, semantics and psychology are all advanced together and are made to account to each other.

Commitment to the Enlightenment project is a constant thread through all of Bunge's publications and educational and social engagements. This began in his early 20s when he was Secretary General of the Federación Argentina de Sociedades Populares de Educación. During this time he wrote his first book, Temas de Educación Popular (1943) dealing with the principles and practice of popular (workers) education. In one essay-'CounterEnlightenment in Contemporary Social Studies'-he writes:

\footnotetext{
The Enlightenment gave us most of the basic values of contemporary civilized life, such as trust in reason, the passion of free inquiry, and egalitarianism. Of course the Enlightenment did not do everything for us: no single social movement can do everything for posterity - there is no end to history. For instance, the Enlightenment did not foresee the abuses of industrialization, it failed to stress the need for peace, it exaggerated individualism, it extolled competition at the expense of cooperation, it did not go far enough in social reform, and it did not care much for women or for the underdeveloped peoples. However, the Enlightenment did perfect, praise, and diffuse the main conceptual and moral tools for advancing beyond itself. (Bunge 1994, p. 40)
}

Bunge believes-contra contemporary individualisms, subjectivisms, constructivisms, and relativisms -that science can, and does, give us knowledge of the natural and social world; and that this knowledge is the only sound basis for social and political reform, and for personal flourishing. He is consequently a critic, indeed a trenchant one, of social forces and academic movements that diminish the intellectual authority of reason and science. 


\section{Systematic Philosophy}

Through to the mid twentieth-century most Western philosophers were systematic philosophers who worked explicitly or implicitly within traditions: Aristotelianism, Thomism, Scholasticism, Cartesianism, British Empiricism, Hegelianism, Marxism, Kantianism, Logical Positivism, Logical Empiricism, Personalism, Existentialism so on. Even where philosophers were not part of a tradition or did not carry a 'party card' there was an assumption that the different areas of one's philosophical inquiry had to cohere and be consistent with each other: that epistemology, ontology, ethics, politics, philosophy of mind, religion, anthropology and even education had all to be fit together and hopefully draw from each other.

It was thought unacceptable, for instance, to be a materialist in ontology and yet believe the mind was immaterial or that souls or mathematical objects had independent existence and could causally act in the natural world; it was regarded as a problem to be an empiricist in epistemology yet believe that knowledge of the world came from revelation, authority or intuition; it was thought that empiricist views of the mind had different educational consequences than Platonist views of the mind; if a philosopher is an ethical utilitarian, then it was thought incumbent on them to give some explanation if they are also a Christian, Jewish or Islamic fundamentalist; likewise espousing liberalism in politics and at the same time embracing dogmatism in education required some explanation; and so on. The assumption was that one's philosophical positions minimally had to cohere and not contradict each other; although the philosophical mansion had many rooms, they were nevertheless thought to be rooms in the one building.

It was widely thought that all of the big philosophical systems had to come to terms with and accommodate the methods and findings of science. It was thought a major deficiency to carry on systematic philosophy without reference to modern science. Most reasonable thinkers thought that philosophical elaboration of epistemology, ontology, metaphysics, ethics or even politics required attention to the methods and achievements of science. A theory of the growth of knowledge or of good reasoning that did not understand and accommodate Newton's, Darwin's or Einstein's achievements was regarded as hardly an epistemological or logical theory at all. Clearly some systems and some philosophers managed this engagement more successfully than others. While the Positivist tradition took science very seriously, the Analytic and Personalist traditions did not do so.

And as philosophers had to pay attention to science, it was thought advantageous that they knew about and had some competence in the field, the more so for philosophers of science. Competence and expertise in science clearly does not entail competence and expertise in philosophy of science; the ranks of scientists who propound ill-informed and silly philosophy is legion. Susan Stebbing's classic unpicking of the philosophical follies and faulty reasoning of the famous English physicists James Jeans and Arthur Eddington was a salutary warning against believing that scientific competence shed philosophical light (Stebbing 1937/1958) Although competence in science was not regarded as a sufficient condition for competent philosophy, nevertheless it was widely thought to be a necessary condition. Anyone doubting the latter proposition need only be reminded of Alan Sokal's devastating 1996 hoax played out on postmodern philosophers (Sokal and Bricmont (1998). Sokal well showed that without minimal scientific competence, philosophical nonsense could pass muster and be published in authoritative journals. 
In the past half-century the pursuit of systemic philosophy, 'big pictures', 'grand narratives' or even cross-disciplinary understanding has waned, with fewer and fewer scholars having serious competence beyond their own increasingly narrow field of research. Indeed in 'postmodern times' even the pursuit of a big picture or grand narrative is widely thought to be in-principle flawed or quixotic. Especially since Lyotard's 1984 denunciation of the 'grand narrative programme' it is widely held that all philosophical questions and pursuits should be local: that epistemology, ethics, politics and other fields should not be universal but be avowedly local-meaning constrained and judged by local cultural norms and practices (Lyotard 1984). This is one of the core convictions, if one might use the term, of postmodernism. And the proportion of philosophers trained and competent in science has probably also declined. The philosophical norm has shrunk from scientifically-informed wide systematic concerns to narrow-focus pursuits.

\section{Liberal Education}

It is especially unfortunate if a narrow focus takes root among school teachers, teacher educators and curricula writers. We recognise that a good music teacher who has classes listen to the 1812 Overture should be able to elaborate a little on why the particular date is there, and say something or have students find out about Napoleon and the historical circumstances of his invasion of Russia. Perhaps take the opportunity to mention Napoleon's cultivation and support of science, mathematics and so on. And in the best of all educational worlds the history teacher teaching about Napoleon in the context of the French Revolution and First Empire might mention or direct students to related musical, mathematical and scientific connections. The same cross-disciplinary pattern can be repeated for most curricular topics if teachers have the appropriate knowledge and interests to see connections between disciplines and subject matters. Teachers are better teachers if they know what is going on in adjacent classrooms and can convey to students something of the interconnectedness of intellectual life. The more so should curriculum writers know what is going on in the adjacent curriculum.

Liberal education endeavours to deepen student understanding of core disciplines such as science, mathematics, language, literature, history, social studies and the arts; and to enrich their appreciation of significant social and cultural achievements. Both are done so as to improve students' own lives and enable them to better appraise and contribute to their own society and culture. No discipline or scholarly field is an island unto itself; it is created, evolves, takes shape and responds in certain cultural, social and intellectual circumstances. This is especially so for science: the history of science is interleaved with that of mathematics, philosophy, technology, commerce, theology, ethics, aesthetics and more generally ideology. All of this constitutes the curricular 'big picture' that the liberal education tradition promotes. Teaching science in a HPS-informed way advances this liberal education programme by showing the connections within science topics and between such topics and the wider intellectual and cultural milieu components of which also appear in the school curriculum. In a number of publications I have shown this for the case of pendulum studies (Matthews 2000) and photosynthesis (Matthews 2009).

In the case of HPS-informed pendulum studies, the inter-connecting curriculum picture is something like: 


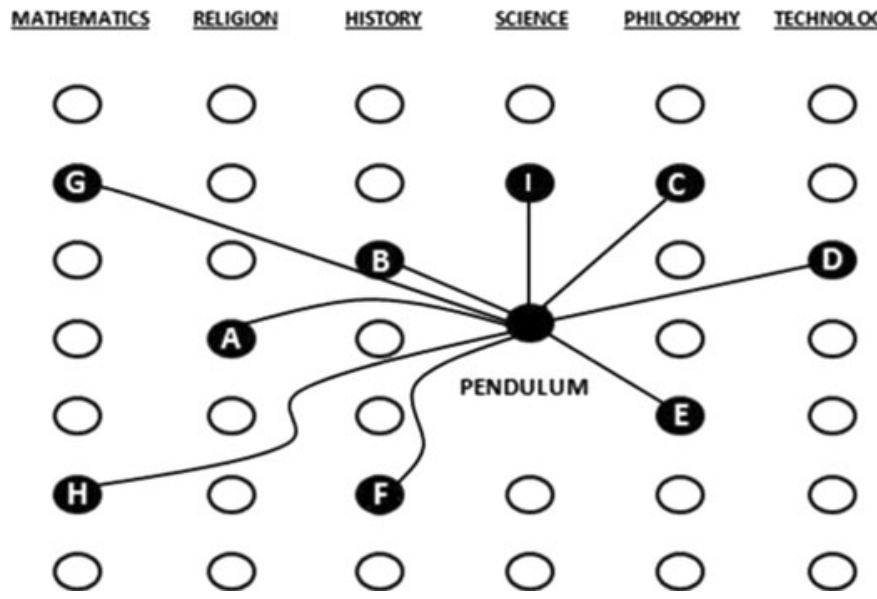

\begin{tabular}{lll}
\hline A design argument & D clock making & G geometry \\
B navigation and longitude & E idealisation and theory testing & H calculus \\
C experimentation & F European trade and colonisation & $\begin{array}{c}\text { I mechanics, Galileo, Huygens } \\
\text { and Newton }\end{array}$ \\
\end{tabular}

Teachers knowledgeable about HPS can replicate the above schema with standard science curriculum topics such as: combustion, photosynthesis, thermodynamics, mechanics, astronomy, cosmology, genetics and evolution. Such a schema brings coherence to curricula where subjects and disciplines are mostly fractured, insular and unconnected; and such schemes encourage and support cross-disciplinary engagement among school teachers and university faculty.

\section{Bunge's Systematism and Chinese Communist Party Philosophy}

Bunge has a positive appreciation of Marx and Engels, saying that: 'they were serious, important social scientists; they pushed liberalism towards the left.; they were materialists on the whole; and they wrote clearly except about dialectics (Bunge 1994, p. 30). But unfortunately they 'learned from Hegel a few lessons that vitiated their whole system' (Bunge 1994, p. 30). The intellectual and cultural horrors associated with Dialectical Materialism in the former USSR and Eastern Bloch countries is well documented; an example of bad philosophy having horrendous social and personal consequences. The case of China is less know and less documented.

In 2011 Bunge was invited to give lectures in China, including three to the Communist Party's School of Marxism. In the first lecture, he expressed his admiration for China:

Nowadays I join the rest of the world in admiring the courageous one-child policy, no less than the sensational achievements in Chinese economy, technology, and natural science over the past few decades. (unpublished lecture)

And then went on in his typically direct manner to say: 
However, I have not come to flatter you. Instead, I came to offer some constructive criticisms of Chinese philosophy. Allow me to start by telling you brutally that your philosophy is primitive and unscientific, and that you should update it in the light of science, logic, and mathematics. The reason for carrying out this task is it that it is unreasonable and even politically hazardous to remain stuck in philosophy's past while advancing so quickly in modernizing the rest of society.

After all, social policies are designed on the basis of a handful of philosophical principles about the nature of the world, human beings, society, and knowledge, as well as ideas about what is worth and just. If any of these guiding principles are wrong, the social policies will fail or worse: they will bring misery. (ibid)

He was particularly scathing of 'Dialectical Materialism' which is a compulsory subject for all Chinese school and university students, and for the propagation of which there are probably tens of thousands of Dialectics professors in Chinese universities. In his words:

To summarize, Marxist ontology and epistemology are in deep trouble because they have remained stagnant or worse due to their attachment to dialectics. But there is hope in materialism, for it is the tacit ontology of science and technology, just as realism is their tacit epistemology. Indeed, all the items handled by scientists and technologists are material, and all of them are assumed to be knowable to some extent. Ideal objects are confined to mathematics, and mysteries to religion. (ibid)

He admired the systematic aspirations of Chinese philosophy and policy, but decried their actual embodiments. Saying that:

Such renewal of ontology requires the parallel renewal of the theory of knowledge and the philosophies of mind, culture, and mathematics. We need a theory of knowledge both realist and going far beyond the so called "reflection theory", which makes no room for invention. We also need a philosophy of mind based on cognitive neuroscience, hence assuming that mental processes are brain processes. The new philosophy of culture should stress that, far from being a by-product of economic activity, culture is creative and has a transformative power, which is particularly strong in the cases of science and technology.

And the new philosophy of mathematics should avoid the extremes of nominalism and Platonism, adopting instead the view that mathematical objects are imaginary, though not on the same level as the artistic fictions, since the former are not arbitrary but subject to laws.

Bunge's systematicism, which extends to ethics and politics, allowed him with consistency to admonish the Chinese authorities for their entrenched abuse and neglect of basic human rights:

Last, but not least, we need philosophies of values, right conduct, and political action, admitting the existence of universal values, such as welfare and solidarity, as well as the norm of justice enshrined in the motto of the First International: No duties without rights, and no rights without duties. All the norms of practical philosophy should be based on science and technology, and they should be regarded as testable in practice: here, as elsewhere in matters of fact, we should stick to realism and shun dogmatism. (ibid)

Who knows what impact these lectures may have had on the Central Committee, but it is clear that only a science-aligned systematic philosophy would be in a position to challenge the resident, deeply-ingrained State-supported philosophy.

\section{Appraising Bunge's Systematicism}

Bunge has developed a philosophical system that may be characterized as: materialist (or naturalist) but emergentist rather than reductionist; systemist rather than either holist or individualist; rational-empiricist rather than either rationalist or empiricist; science- 
oriented; and exact, that is, built with the help of logical and mathematical tools rather than depending upon purely verbal articulation. He maintains that:

Physics cannot dispense with philosophy, just as the latter does not advance if it ignores physics and the other sciences. In other words, science and sound (i.e., scientific) philosophy overlap partially and consequently they can interact fruitfully. Without philosophy, science loses in depth; and without science philosophy stagnates. (Bunge 2000b, p. 461)

This special issue brings together philosophers, biologists, sociologists, logicians, cognitive scientists, economists, mathematicians and physicists to examine facets of Mario Bunge's systematic philosophy and to appraise its contribution to important issues in current philosophy.

These issues include:

- What are the genuine ontological and epistemological consequences of quantum mechanics?

- How can scientific realism be articulated so as to reconciled with the long history of false theories in science?

- How can fallibilism about science be advanced whilst avoiding relativism?

- Is metaphysical naturalism an ontological presupposition of science or merely a methodological presupposition?

- What is the ontological status of virtual processes in physics and do they have a different status from idealisations in physics and science more generally?

- Do modern neurosciences require a new model of organizational cognition?

- Is fictionist materialism an adequate ontology for mathematics?

- Is reality (the world, nature, society) ontologically layered? If so, are there emergent relations between layers?

- Do social wholes have existence and causal effectiveness or must all social explanations be reduced to individual action?

- Should modern computational cognitive science ("the brainless synthesis inspired by idealism", according to Bunge) be replaced by psychobiology ("the brain-centered synthesis stimulated by emergentist materialism")?

- Are there ecological mechanisms and do they have a role in explaining, predicting, and unifying ecological facts, and designing and interpreting experiments?

- Is a systematic philosophy required to conceptualise and understand the ways in which technological development has impacted on economic development, ecological stability and poverty in Latin America and to formulate effective and morally sound policies to address such impacts?

- How do we formalize the notion of System in ontology and can better formalisations lead to better modelling of material systems?

An underlying theme of all contributions is to examine the possibility and desirability of contemporary systematic philosophy; and if desirable what are the educational and institutional requirements for promoting such approaches to philosophy?

\section{References}

Bunge, M. (1943). Temas de educación popular. Buenos Aires: El Ateneo.

Bunge, M. (1944). A new representation of types of nuclear forces. Physical Review, 65, 249.

Bunge, M. (1945). Neutron-proton scattering at 8.8 and $13 \mathrm{MeV}$. Nature, 156, 301.

Bunge, M. (1955). Strife About Complementarity. British Journal for the Philosophy of Science, 6, 1, 141. 
Bunge, M. (1956). Survey of the interpretations of quantum mechanics. American Journal of Physics, 24, $272-286$.

Bunge, M. (1959) Causality and Modern Science. Cambridge: Harvard University Press. Third Revised Edition, New York: Dover Publications, 1979.

Bunge, M. (1962). Intuition and science. Englewood Cliffs, NJ: Prentice-Hall.

Bunge, M. (Ed.). (1964). The critical approach: Essays in honour of Karl Popper. Glencoe: Free Press.

Bunge, M. (1966) Mach's critique of Newtonian mechanics. The American Journal of Physics, 34, 585-596.

Reproduced in J. Blackmore (ed.), Ernst Mach-A deeper look (pp. 243-261). Dordrecht: Kluwer Academic Publishers, (1992).

Bunge, M. (Ed.). (1967a). Delaware seminar in the foundations of physics. New York: Springer.

Bunge, M. (1967b). Analogy in quantum mechanics: From insight to nonsense. The British Journal for Philosophy of Science, 18, 265-286.

Bunge, M. (1967c). Foundations of physics. New York: Springer.

Bunge, M. (1967d). Scientific research 1, the search for system. New York: Springer.

Bunge, M. (1967e). Scientific research 2, the search for truth. New York: Springer.

Bunge, M. (Ed.). (1971). Problems in the foundations of physics. New York: Springer.

Bunge, M. (Ed.). (1973a). Exact philosophy. Dordrecht: Reidel.

Bunge, M. (1973b). Method, model and matter. Dordrecht: Reidel.

Bunge, M. (1974a). Treatise on basic philosophy. Vol 1, sense and reference. Dordrecht: Reidel.

Bunge, M. (1974b). Treatise on basic philosophy. Vol. 2, interpretation and truth. Dordrecht: Reidel.

Bunge, M. (1977a). Emergence and the mind. Neuroscience, 2, 501-509.

Bunge, M. (1977b). Levels and reduction. American Journal of Physiology, 2, 75-82.

Bunge, M. (1977c). The interpretation of Heisenberg's inequalities. In H. Pfeiffer (Ed.), Denken und Umdenken: zu Werk und Wirkung von Werner Heisenberg (pp. 146-156). Munich: Piper.

Bunge, M. (1977) The philosophical richness of technology. In F. Suppe \& P. D. Asquith (Eds.), PSA 2 (pp. 153-172).

Bunge, M. (1977e). Treatise on basic philosophy. Vol. 3, the furniture of the world. Dordrecht: Reidel.

Bunge, M. (1979). Treatise on basic philosophy. Vol.4, a world of systems. Dordrecht: Reidel.

Bunge, M. (1980). The mind-body problem. Oxford: Pergamon Press.

Bunge, M. (1981). Scientific materialism. Dordrecht: Reidel.

Bunge, M. (1983a). Treatise on basic philosophy. Vol.5, exploring the world. Dordrecht: Reidel.

Bunge, M. (1983b). Treatise on basic philosophy. Vol.6, understanding the world. Dordrecht: Reidel.

Bunge, M. (1985) Treatise on Basic Philosophy. Vol.7, Philosophy of Science and Technology Part 1. Dordrecht: Reidel.

Bunge, M. (1985) Treatise on Basic Philosophy. Vol.7, Philosophy of Science and Technology Part 2. Dordrecht: Reidel.

Bunge, M. (1989) Treatise on basic philosophy. Vol. 8, ethics: the good and the right. Dordrecht: Reidel.

Bunge, M. (1991). A critical examination of the new sociology of science: Part 1. Philosophy of the Social Sciences, 21(4), 524-560.

Bunge, M. (1992). A critical examination of the new sociology of science: Part 2. Philosophy of the Social Sciences, 22(1), 46-76.

Bunge, M. (1994). Counter-enlightenment in contemporary social studies. In P. Kurtz \& T. J. Madigan (Eds.), Challenges to the enlightenment: In defense of reason and science (pp. 25-42). Buffalo, NY: Prometheus Books.

Bunge, M. (1996). In praise of intolerance to charlatanism in academia. In P. R. Gross, N. Levitt, \& M. W. Lewis (Eds.), The flight from science and reason (pp. 96-115). New York: New York Academy of Sciences.

Bunge, M. (1998). Social science under debate: A philosophical perspective. Toronto: University of Toronto Press.

Bunge, M. (2000a). Energy: Between physics and metaphysics. Science \& Education, 9(5), 457-461.

Bunge, M. (2000b). Philosophy from the outside. Philosophy of the Social Sciences, 30(2), 227-245.

Bunge, M. (2001). Philosophy in crisis: The need for reconstruction. Amherst NY: Prometheus Books.

Bunge, M. (2003). Velocity operators and time-energy relations in relativistic quantum mechanics. International Journal of Theoretical Physics, 42(1), 135-142.

Bunge, M. (2004). Emergence and convergence. Toronto: University of Toronto Press.

Bunge, M. (2006). Chasing reality: Strife over realism. Toronto: University of Toronto Press.

Bunge, M. (2009). Political philosophy. New Brunswick, NJ: Transactions Publishers.

Bunge, M. (2010). Matter and mind: A philosophical inquiry. Dordrecht: Springer.

Bunge, M. (2011). Knowledge: Genuine and Bogus. Science \& Education, 20(5-6), 411-438. 
Bunge, M. (2012a). Wealth and well-being, economic growth, and integral development. International Journal of Health Services, 42, 65-76.

Bunge, M. (2012b). The correspondence theory of truth. Semiotica, 188, 65-76.

Bunge, M. (2012c). Evaluating philosophies. Boston Studies in the Philosophy of Science, 295, 2012.

Bunge, M., \& Ardila, R. (1987). Philosophy of psychology. New York: Springer.

Lyotard, J.-F. (1984). The postmodern condition: A report on knowledge. Minneapolis: University of Minnesota Press.

Mahner, M. (Ed.). (2001). Scientific realism: Selected essays of Mario Bunge. Amherst, NY: Prometheus Books.

Mahner, M., \& Bunge, M. (1996). Is religious education compatible with science education? Science \& Education, 5(2), 101-123.

Mahner, M., \& Bunge, M. (1997). Foundations of biophilosophy. New York: Springer.

Matthews, M. R. (2000). Time for science education: How teaching the history and philosophy of pendulum motion can contribute to science literacy. New York: Plenum Press.

Matthews, M. R. (2003). Mario Bunge: Physicist and philosopher. Science \& Education, 12(4-5), 431-444.

Matthews, M. R. (2009). Science and worldviews in the classroom: Joseph Priestley and photosynthesis. In M. R. Matthews (Ed.), Science, worldviews and education (pp. 271-302). Dordrecht: Springer.

Matthews, M. R., Gauld, C. F., \& Stinner, A. (Eds.). (2005). The pendulum: Scientific, historical, philosophical and educational perspectives. Dordrecht: Springer.

Quine, W. V. O. (1985). The time of my life: An autobiography. Cambridge MA: Bradford Books.

Rohrlich, F. (1987). From paradox to reality: Our basic concepts of the physical world. Cambridge: Cambridge University Press.

Sokal, A. (1996). Transgressing the boundaries: Toward a transformative hermeneutics of quantum gravity. Social Text, 46(47), 217-252.

Sokal, A., \& Bricmont, J. (1998). Intellectual impostures. London: Profile Books.

Stebbing, L. S. (1937/1958). Philosophy and the Physicists. New York: Dover Publications. 